Fecha de recepción: marzo 2020 Fecha de aceptación: abril 2020 Versión final: junio 2020

\section{El tango en la marea verde. Una mirada de género sobre las figuras de lo femenino en el tango actual}

Sofía Cecconi ${ }^{(1)}$

Resumen: la letrística del tango ha sido un territorio privilegiado para la manifestación de diversas figuras de género. Entre las femeninas, algunas han devenido clásicas: la milonguita, esa mujer con aspiraciones de ascenso social que deja el barrio y huye hacia el centro en busca de una vida mejor, siempre vista con malos ojos por la moral dominante; y la madre, mujer abnegada, buena y perfecta a los ojos del hijo, capaz del mayor de los sacrificios en pos de la felicidad de los demás. Ambas figuras, la heroína materna y la contraheroína milonguita, se nutrieron de y cristalizaron en un imaginario social que concebía a la mujer con base en un esquema binario: la buena mujer era la mujermadre, orientada hacia el prójimo, siempre dispuesta a colocarse en segundo plano. Y por contraste, la mala mujer era aquella que no sólo huía de su destino de clase sino también de su destino de género, aquella que dejaba el hogar natal sola, siempre tentada por varones que le prometían una vida mejor. En la narrativa tanguera clásica, esta mujer gozosa, desafiante de la moral y las normas dominantes, se opone por el vértice a aquella otra que renuncia a un destino autónomo, dos caras de una moneda que presenta a las mujeres ocupando un claro lugar en ese esquema normativo.

Desde la emergencia y consolidación en la letrística del tango de aquellas figuras han pasado unos cuantos años y una marea de experiencias que han trastocado los modos tradicionales de concebir las diferencias de género. En las últimas dos décadas asistimos a un resurgimiento del tango en sus múltiples facetas: el tango bailado ha proliferado de milongas y espacios de encuentro; la producción musical de tango se ha revitalizado con una multiplicación de discos y propuestas que ensanchan sus fronteras; y el tango canción también ha visto incrementar su acervo gracias al aporte de nuevas generaciones de letristas que incorporan nuevas miradas y tropos. Uno de esos aportes viene de la mano de la producción de mujeres, que escriben letras de tango retomando aquellos arquetipos de género para deconstruirlos y rearmarlos en función de las nuevas claves epocales. En este artículo analizaremos el modo en que se presentan en estas nuevas producciones aquellas figuras clásicas de lo femenino; el rol que se le asigna a las mujeres; y de modo más general, la manera en que las nuevas letras de tango recuperan, tuercen y rompen la tradición al presentar a las figuras femeninas. Lo haremos a partir del análisis de un corpus de letras producidas por mujeres, producciones que introducen en el género musical nuevas voces e imaginarios y tiñen al tango de nuevos colores. El tango "verde" es un tango contemporáneo que expresa y a la vez construye un nuevo imaginario, un tango en el que el diálogo con el feminismo se vislumbra como un camino posible. 
Palabras clave: tango - género - figuras de género - letras de tango - feminismo - mujer - madre - milonguita.

[Resúmenes en inglés y portugués en las páginas 184-185]

(1) Sofía Cecconi. Socióloga y Doctora en Ciencias Sociales por la Universidad de Buenos Aires. Realizó estudios de posgrado en la Freie Universität zu Berlin. Actualmente se desempeña como docente en la Facultad de Ciencias Sociales de la UBA y en la UNDAV. Fue becaria doctoral y posdoctoral del Consejo Nacional de Investigaciones Científicas y Técnicas (CONICET) con asiento en el Instituto de Investigaciones Gino Germani de la UBA. Sus principales áreas de interés son la sociología de la cultura, el tango, los jóvenes, la temática del cuerpo y las cuestiones de género. Ha publicado diversos artículos en libros y revistas internacionales sobre estos tópicos.

\section{Introducción}

La letrística del tango ha sido un territorio privilegiado para la manifestación de diversas figuras de género. Entre las femeninas, algunas han devenido clásicas: la milonguita, esa mujer con aspiraciones de ascenso social que deja el barrio y huye hacia el centro en busca de una vida mejor, siempre vista con malos ojos por la moral dominante; y la madre, mujer abnegada, buena y perfecta a los ojos del hijo, capaz del mayor de los sacrificios en pos de la felicidad de los demás. Ambas figuras, la heroína materna y la contraheroína milonguita, se nutrieron de y cristalizaron en un imaginario social que concebía a la mujer con base en un esquema binario: la buena mujer era la mujer-madre, orientada hacia el prójimo, siempre dispuesta a colocarse en segundo plano. Y por contraste, la mala mujer era aquella que no sólo huía de su destino de clase sino también de su destino de género, aquella que dejaba el hogar natal sola, siempre tentada por varones que le prometían una vida mejor. En la narrativa tanguera clásica, esta mujer gozosa, desafiante de la moral y las normas dominantes, se opone por el vértice a aquella otra que renuncia a un destino autónomo, dos caras de una moneda que presenta a las mujeres ocupando un claro lugar en ese esquema normativo.

Desde la emergencia y consolidación en la letrística del tango de aquellas figuras han pasado unos cuantos años y una marea de experiencias que han trastocado los modos tradicionales de concebir las diferencias de género. En las últimas dos décadas asistimos a un resurgimiento del tango en sus múltiples facetas: el tango bailado ha proliferado en milongas y espacios de encuentro; la producción musical de tango se ha revitalizado con una multiplicación de discos y propuestas que ensanchan sus fronteras; y el tango canción también ha visto incrementar su acervo gracias al aporte de nuevas generaciones de letristas que incorporan nuevas miradas y tropos. Uno de esos aportes viene de la mano 
de la producción de mujeres, que escriben letras de tango retomando aquellos arquetipos de género para deconstruirlos y rearmarlos en función de las nuevas claves epocales y generacionales. En este artículo analizaremos el modo en que se presentan en estas nuevas producciones aquellas figuras clásicas de lo femenino; el rol que se le asigna a las mujeres; y de modo más general, la manera en que las nuevas letras de tango recuperan, tuercen y rompen la tradición al presentar a las figuras femeninas. Lo haremos a partir del análisis de un corpus de letras escritas por mujeres, producciones que introducen en el género musical nuevas voces e imaginarios y tiñen al tango de nuevos colores. El tango "verde" es un tango contemporáneo que expresa y a la vez construye un nuevo imaginario, un tango en el que el diálogo con el feminismo se vislumbra como un camino posible.

El trabajo se organiza en cuatro partes. En la primera hacemos una breve digresión conceptual acerca de la noción de "género" y sus derivaciones en la teórica feminista para situar el análisis que realizamos en ese paradigma. En la segunda, revisamos las figuras tradicionales de género que el tango ha producido siguiendo el aporte de diversos autores y autoras. En el tercer apartado nos metemos de lleno en el análisis de las figuras que se articulan en las nuevas producción escritas por mujeres, mostrando como tuercen y resignifican la tradición. El trabajo concluye con unas reflexiones finales.

\section{Género y figuras de género}

Las cuestiones de género hace unos años se han convertido en tema de agenda pública. Varias olas feministas se sucedieron desde mediados del siglo XX hasta el presente, para que la marea verde copase las calles y las mujeres y las problemáticas asociadas con la desigualdad y la violencia que la sociedad ejerce sobre sus cuerpos adquirieran visibilidad. Términos como "patriarcado", "diversidad", "diferencia sexual", "roles de género", "sororidad", entre muchos otros, comienzan a circular cada vez con mayor fuerza y adquirir un lugar en el lenguaje diario. Esas voces, que antes apenas un puñado de "locas fanatizadas" -según una visión socialmente extendida- levantaban como herramientas para entender la posición de las mujeres en la sociedad y bregar por el fin de la subordinación y la desigualdad, son hoy palabras que forman parte del vocabulario cotidiano de una gran parte de las mujeres, y también de varones. Muchas de ellas configuran el sentido común de las más jóvenes, que son las protagonistas indiscutidas de este momento histórico en nuestro país, pero con una fuerza que contagia a las mayores, muchas de la cuales al ver y escuchar a sus propias hijas, reinterpretan muchos aspectos de sus propias vidas y relaciones en clave feminista.

Ante este despertar, claro, no faltan los sectores conservadores que denuncian la invasión de "feminazis" radicalizadas. Pero su violencia discursiva, sirve de aliciente para vigorizar las posiciones y refinar los argumentos. Es cierto que no todas las mujeres comparten de igual modo las banderas del feminismo; es cierto que algunas vinculadas con aquellos sectores incluso defienden banderas opuestas, afirmando que las mujeres no deben tener derechos sobre sus propios cuerpos; es cierto que al interior del movimiento hay una pluralidad de posiciones en muchos temas de debate. Pero lo que define el momento 
actual en nuestro país es que las mujeres como colectivo ganaron la calle, sus reclamos de igualdad se hicieron visibles, su grito de denuncia contra los femicidios alcanzó tal magnitud y reverberación que sus ecos cruzaron los océanos, multiplicándose en otros continentes; que su lucha por la legalización del aborto se encuentra en su momento más álgido, con altísimas probabilidades de, finalmente, triunfar.

Las cuestiones de género, así, se visibilizaron. Decimos “visibilizaron” porque estas cuestiones existían, claro. Pero la sociedad las interpretaba de otra manera. El sentido común hasta hace no muchos años asignaba a la mujer un lugar subordinado al varón porque, según esa visión, ella "naturalmente" era inferior. En ese imaginario, tal inferioridad "natural", por lo general, se asociaba con su capacidad reproductiva, que la conducía, inexorablemente, a parir, cuidar de los niños y de la casa, bregar por la salud de los miembros de la familia y organizar la vida doméstica, mientras que los varones se ocupaban de "lo importante", que, por supuesto, sucedía fuera de las puertas del hogar: el trabajo, la política, la vida pública.

El feminismo surge como un movimiento que busca romper con esta idea, demostrar el carácter construido y cultural que supone pensar las relaciones entre varones y mujeres de ese modo. Es así que va enarbolar un término que le resultará fundamental como herramienta para deconstruir aquello que se postulaba como natural: el género. "Mujer no se nace, se hace", sostenía Simone de Beauvoir. Y con esto daba a entender de una manera categórica que nada en la biología de la mujer explicaba su subordinación al varón, tal como la sociedad lo establecía. Que ese ser-mujer-subordinado era el resultado, el producto, de lo que la cultura hacía con ese cuerpo sexuado. Beauvoir hacía notar, de esta manera, que nada en la naturaleza biológica determina lo que "una mujer es", con lo cual no es en ese terreno donde deben buscarse los orígenes de su opresión.

El término "género" entonces surge para dar cuenta de esta distancia entre naturaleza y cultura que, en el terreno de la diferencia sexual, se expresaría de este modo: sexo sería al género, lo que naturaleza a cultura. Una de las primeras autoras feministas que propuso un uso sistemático de este concepto fue Gayle Rubin (1986). Su noción central, el sistema sexo/género, configuró un aporte esencial para comenzar a dar sustento teórico al hecho de que el "ser mujer" es producto de una construcción sociocultural, el género, que se impone al sexo "natural" mediante un proceso que adquiere características específicas. En esta visión, el género sería un atributo que se asocia con ciertos cuerpos sexuados: lo masculino para el varón, lo femenino para la mujer. El feminismo continuará desarrollando el concepto a partir de diversos aportes. Entre ellos se puede mencionar los de Teresa de Lauretis (1987), quien también destaca la importancia de la dimensión cultural en la construcción social del género, pero va a proponer pensarlo como un efecto producido en los cuerpos: según esta definición, el género es una construcción, una representación, producto de variadas tecnologías sociales, discursos y prácticas.

No es nuestra intención hacer una historia del concepto ni mucho menos, solo mencionar algunos hitos en el desarrollo de la noción. En ese sentido, debemos señalar que luego de fracturas en el movimiento feminista, de la aparición de disidencias internas y de voces que no se sentían incluidas en las categorías analíticas dominantes, la teoría feminista amplió su base de reflexión y su sujeto de enunciación para incorporar a las denominadas "diversidades sexuales". Dentro de ese universo, una autora que sin dudas 
marcó el camino de la reflexión sobre la temática de género fue Judith Butler, referente de lo que se conoce como los "estudios queer". Con sus aportes, el feminismo de la tercera ola deconstruye aun más "lo que una mujer es", para revertir el eje que ponía en el centro de la cuestión la materialidad del cuerpo sexuado (la "biología") modelada luego por "la cultura" (el género como un atributo otorgado a un cuerpo). Para Butler primero hay discurso y ese discurso crea la materialidad del cuerpo. En este marco, el "género" deja de ser un atributo de los cuerpos para convertirse en un hacer, una performance, que va otorgándole sentido y materialidad al cuerpo sexuado: el género para la autora se constituye a partir de un acto performativo que deviene de una "práctica reiterativa y referencial mediante la cual el discurso produce los efectos que nombra" (Butler, 2001).

Más allá entonces de los desplazamientos semánticos que el concepto fue atravesando, más allá de la radicalidad con la que se conciba teóricamente su alcance, e incluso de la voluntad política por superar los efectos que ejerce sobre los sujetos y de las normas que les impone, el concepto continua siendo potente para pensar una diferencia estructurante de nuestras sociedades. ${ }^{1}$

En este trabajo, como señalamos, nos centramos en un corpus particular para analizar esta cuestión: el de las letras de tango. El tango como hecho artístico puede analizarse a través de una perspectiva de género. El baile, por ejemplo, es un territorio privilegiado donde poner el foco para observar, en la performance, una performatividad de género que se despliega en el movimiento coreográfico de los cuerpos. Hemos tratado esta cuestión en otros trabajos (Cecconi, 2009 y 2015). En este nos interesa centrarnos en otra dimensión del fenómeno que ha adquirido, recientemente, un desarrollo notable. Si bien es cierto que siempre hubo letristas mujeres dentro del universo de compositores de tango, en el pasado muchas de ellas debieron travestirse (firmar con alias de varón) para poder trascender. También es cierto que el volumen de obras escritas por mujeres era significativamente menor a la producción realizada por varones. Lo que trasciende las diferentes épocas del tango, en cambio, es la presencia de representaciones de lo femenino en sus letras. Las mujeres aparecen una y otra vez como figuras cuyos trazos responden a configuraciones que tienen carácter epocal. Es decir, si es cierto existen figuras arquetípicas de lo femenino en el tango tradicional, y que esas figuras representaban en gran medida el imaginario masculino en torno a ellas (Saikin, 2004), debemos señalar que en el presente emergen otras figuras, surgidas de voces otras, que introducen figuras de género en otra clave.

Entendemos por "figuras de género" los modos en que lo femenino y lo masculino se configura en las letras de tango a través de la atribución de ciertas características que vinculan el "ser mujer" o "ser varón", en un esquema tradicionalmente binario, con rasgos definidos. De esas figuras nos interesan especialmente las femeninas, para analizar cuáles son las normas, las actitudes y los comportamientos que las regulan, los atributos que se le asignan, y los valores con los que se le asocian.

Considerando este punto de partida, pasaremos revista a las formas que tal cuestión asumió en el tango tradicional, siguiendo aportes de investigaciones que hoy han devenido clásicas y otras más recientes, para iluminar en el apartado siguiente, por contraste, las características más sobresalientes de las figuras del presente. 


\section{Figuras de género en el tango "tradicional"}

Si bien la relación de las letras del tango con la época no es lineal, pues como Matamoro (1969 y 1971), Ulla (1982 [1967]) y Vilariño (1965), entre otros, han planteado, las letras clásicas del tango de algún modo se erigen sobre la base de una nostalgia por un tiempo pasado y, por lo tanto, hacen referencia a un tiempo que ya no es; ese vínculo con la realidad de la que emergen existe y se articula en ellas, sea que retomen temáticas y cuestiones sociales circundantes para expresarlas en sus letras, sea por el contrario, que reconstruyan a través de la nostalgia de lo que fue, la realidad contemporánea de un mundo rechazado. Hasta hace no muchos años los compositores de las letras de tango eran en su enorme mayoría, varones. Las letristas mujeres existieron, por supuesto pero eran excepciones en un mundo letrado dominado por escritores que introducían las figuras y las voces femeninas a través del tamiz de su propia posición de sujeto. ${ }^{2}$ A su vez, si bien hay tangos escritos para ser cantados por mujeres y donde el yo lírico es femenino, estos constituyen una minoría. ${ }^{3}$ En ambos casos, entonces, la mediación de la voz de la mujer y la construcción de las figuras y el universo de lo femenino, quedaban permeados por esa posición masculina que les daba voz. Pero más allá de esos casos, que resultan minoritarios en el conjunto, en la gran mayoría de las letras de tango, la experiencia de las mujeres, sus modos de estar en el mundo, de concebirse a sí mismas y a los demás, sufría una suerte de distorsión producida por una voz otra que, como un ventríluoco, las hacía hablar. Y por ello, esas figuras de género dan cuenta de los modos dominantes (masculinos) de representarlas. ${ }^{4}$

Vilariño (1965) es una de las primeras autoras en abordar con herramientas provenientes del análisis del discurso, la producción escrita del tango, en un texto ya devenido clásico, en el que analiza los diferentes temas y motivos que le son característicos. Entre los que menciona como recurrentes, algunos poseen una relación directa con los modos en que se presenta y representa a la mujer. Se trata de figuras género que vinculan lo femenino con tres grandes universos: "la madre", la "mujer que triunfa en la mala vida" y la "linda que se pierde". Estas tres figuras se reiteran en numerosas composiciones de diversas épocas, en las cuales persisten más allá del paso del tiempo. Entre los años 20 y los 50 del siglo XX, por definir un período temporal para este tango "tradicional", la figura de la madre y la milonguita, en su versión de "linda que se pierde" o "mujer de la mala vida", son constantes que delinean modelos femeninos nítidos.

En cuanto al primero, siguiendo a Vilariño, "La madre concita en el tango unánime piedad, amor, ternura. (...) Esta y genéricamente toda madre, es siempre santa, abnegada, comprensiva, apoyo sin declinaciones, lo único en qué confiar, el amor sincero y puro al que se vuelve al fin. Es notable esta idealización en una literatura que si bien ha idealizado su medio lo ha hecho en sentido de adaptarlo a ciertos cánones pero casi nunca ocultando el lado negro de las cosas. (...) Pero la madre siempre es sin tacha." (Vilariño, 1965: 174-175) Así, cuando lo femenino se asocia con la figura de la madre, y agregamos, con la noviecita pura y respetable que la remeda, la mujer se torna un ser idealizado, sinónimo de pureza, de bondad, de amor perfecto y sin fisuras. La madre puede sufrir por el hijo, vivir en la miseria, padecer las injusticias más amargas, pero jamás le hará un reproche y lo recibirá siempre con los brazos abiertos y con una sonrisa que aplacará cualquier dolor. De este modo, es claro que cuando la mujer es presentada en su función maternal, se produce 
una fuerte idealización que la convierte en un ser perfecto, siempre dispuesta a dar cobijo, afecto y protección cuando, alicaído, el hijo regresa al hogar por una traición... de la cual siempre es culpable otra mujer.

Es que esta mujer-madre-perfecta se nutre de otra figura que define sus contornos: otro elemento constante de las letras es la oposición madre-amante, expuesta en términos de franca rivalidad. Justamente es esa amante la que lleva al hijo a abandonar a la madre, esa amante la que traiciona y hace sufrir. Y es en torno de esa figura, por lo tanto, donde se condensan todos los valores negativos que lo femenino posee. La amante se presenta como una hechicera que embauca al hijo, que lo embruja con sus encantos amatorios y su capacidad de seducción sin fin. Es por ella que el hijo abandona el hogar, el barrio, a la propia madre. Y cuando finalmente se produce el desencanto, porque esa mala mujer lo abandona, yéndose con otro que le ofrece una vida mejor, entonces el hijo regresa al seno materno. Así, la figura de la amante es una de las formas que adopta lo femenino asociado a mujeres que triunfan en la mala vida. Vilariño distingue otros dos motivos para esa figura: la que lo hace engañada y aquella que da "el mal paso" a sabiendas de lo que está haciendo, tentada por las luces de la ciudad, el lujo y los placeres de la opulencia. En el primer caso las letras de tango muestran a una mujer que fue engañada por un hombre sin escrúpulos, que la seduce prometiéndole amor eterno, para dejarla luego abandonada en el cabaret, donde ella permanecerá triste, nostálgica, sola y arrepentida por el mal paso que dio, por abandonar el barrio, la casa paterna, la pureza del hogar. Lo que diferencia este caso del segundo es que, si bien en este último también puede haber un seductor que la tienta, lo principal es la ambición material: la promesa de riquezas, de placeres, de ropas es lo que lleva a esta mujer a dar "el mal paso". Lo que aquí se manifiesta es un interés centrado en el dinero antes que la obnubilación por un amor romántico. Pero la historia se precipita siempre en un final idéntico y trágico: tanto la mujer que huye de su destino de género, siguiendo a un hombre del que se enamora y la lleva a romper los mandatos que la obligan a permanecer en el espacio doméstico hasta el matrimonio; como aquella que huye de su destino de clase, buscando dejar atrás una vida de carencias y pobreza, ambas, encuentran la miseria y la desdicha al llegar a la vejez, luego de haber atravesado sus días de juventud ejerciendo la prostitución en el cabaret. ${ }^{5}$

Archetti (1998 y 2003), analizando la cuestión desde el punto de vista de la configuración de la masculinidad en el tango, interpreta que el meollo del asunto en el tango está en la dificultad que el yo lírico encuentra en el cumplimiento del amor romántico. Ante esa situación plantea que "una posible solución para las mujeres y para sí mismo [para el varón] sería el retorno a las formas del amor y la castidad inmanentes a los papeles familiares tradicionales. En tal contexto discursivo, la imagen de la milonguita y la del hijo ingrato contrasta con la imagen de la madre idealizada. Se exalta el amor maternal relacionándolo con ideas de pureza, sufrimiento, sinceridad, generosidad y fidelidad. El amor materno es el único sentimiento perdurable" (Archetti, 1998: 296-297). En este contexto, se le atribuye a la madre la cualidad de la abnegación sin ambages, de pureza, de deber moral, en un vínculo con el hijo que se rige por un amor completo y sin fisuras. Frente a esta figura el autor señala un hecho contundente: la milonguita no puede convertirse en madre, así como el mundo de la madre excluye la vida nocturna propia de la esfera pública. El contraste entre ambas es absoluto. 
Así, lo femenino en el tango tradicional se organiza en dos figuras claramente opuestas y complementarias. Cuando la mujer es madre se condensa en ella todo aquello reconocido como valor positivo. Cuando decide otro destino, autónomo, alejado de la reproducción biológica y de los quehaceres que socialmente se reconocen como obligatorios para su género, entonces todo lo que ella es, se valora negativamente. La ecuación es clara: si la mujer reproduce aquello que la norma establece, si obedece al mandato "natural" de la maternidad, entonces su pureza es infinita. En cambio, si se desvía, si acaso osa con pretender cierto grado de autonomía, entonces es traicionera, embaucadora, de poco fiar. Cara y ceca de una misma construcción donde lo negativo y lo positivo se organizan en dos figuras presentadas como oposiciones irreconciliables que definen el universo femenino.

Si bien estas figuras han sido históricamente dominantes, antes de que el tango canción se consolidara como género y estas figuras femeninas se articularan en su letrística, hubo una época previa, la época de los orígenes, donde el tango aun no poseía letras en sentido estricto. Las letrillas de aquel entonces circulaban tarareadas, en la oralidad propia de las culturas populares, aunque algunas han llegado a formularse por escrito, con las deformaciones que toda apropiación letrada impone a lo que hasta entonces circulaba como palabra hablada. Esas letrillas conforman otro corpus con el que analizar los modos en que se construían las figuras femeninas en aquel momento.

Una autora que ha indagado ese período, comparando el tango prostibulario con el posterior, adecentado, es Magalí Saikin (2004). ${ }^{6}$ La autora plantea que en esos tangos lo femenino define sus contornos en el marco de la tradicional dicotomía varón/mujer que se asocian con valores positivos/negativos, respectivamente, aunque con ciertas peculiaridades. En estas primeras letrillas, entonces, la figura de la madre no es tan relevante como la de la mujer del arrabal. Esta mujer aparece como un ser explotado sexualmente por un cafisho, que la golpea, la violenta y además vive de ella. Hay una ambigüedad aquí, ya que el varón posee algunos rasgos feminizados (básicamente, no trabaja, tiene una excesiva preocupación por su apariencia, algo que lo torna "femenino" para la moral de la época), mientras que la mujer es "brava", puede vestir de manera algo masculina y ejercer la violencia para defender a su hombre. ${ }^{7}$ Más allá de esto, el varón se asocia con la superioridad física, la capacidad de ejercer el castigo corporal sobre la mujer ("darle biaba"), se lo presenta como "vivo", calculador, suspicaz, mentiroso, interesado y materialista. Estos valores, a los que podría adjudicarse un carácter negativo, en el tango prostibulario se presentan positivamente al vincularse con ese varón dueño del cuerpo femenino prostituido. En este contexto, la mujer se asocia con la inferioridad física y la aceptación pasiva y abnegada del castigo como "algo merecido"; se la presenta como tonta e ingenua frente a las intenciones del varón, engañada, explotada, desinteresada e idealista. Pero, nuevamente, siguiendo a Saikín, si estos elementos podrían hacer suponer una vinculación de lo femenino con valores de carga positiva, esto no ocurre, ya que en este tango marginal, esas cualidades que en otros ámbitos podrían funcionar como rasgos valiosos, poseen un carácter distinto. Según el planteo de la autora, cuando el tango se adecenta esto se invierte, la moral se introduce en el tango como algo central: muchos de aquellos valores o elementos asociados con rasgos masculinos pasan ahora concebirse como femeninos, y con ello la carga valorativa se trastoca. El varón presenta entonces una superioridad moral: se lo describe con un ser fiel, ingenuo ante el "engatusamiento" del que es objeto por esa mujer que lo 
abandona, idealista, generoso, capaz de perdonar. La mujer, en cambio, esa que cayó en el cabaret, es presentada como un ser inferior moralmente, infiel, calculadora, mentirosa, materialista, egoísta y traicionera. Frente a la traición no siempre el varón reacciona con resignación. Por el contrario, no son pocos los tangos donde sobreviene la venganza y la violencia, que se presenta en estas letras como una solución válida y natural ante el "desvío femenino".

En un trabajo aun no publicado planteamos la ambigüedad en la construcción de género de esta primera etapa del tango, en la medida en que lo femenino no se ajusta estrictamente a ese imaginario que vincula la mujer con lo doméstico, lo sumiso, lo pasivo. En el tango prostibulario, figuras como "La Taquera" o La Moreira ${ }^{8}$ configuran mujeres con dobleces: fuertes, desafiantes, proveedoras, de rasgos masculinos en el vestir y la gestualidad, pero a la vez sometidas a su compañero, violentadas y golpeadas. Aun cuando los primeros rasgos que dan cuenta de una fortaleza y una posición en gran medida activa y dominante sean notorios y relevantes, estas mujeres aceptan con abnegación esa violencia como algo "natural" y propio de la posición de sujeto que les toca. Esa violencia, entonces, que definiría una virilidad ejercida sobre un cuerpo cosificado, es asumida y consentida como estructurante de un vínculo y del natural orden de las cosas.

En síntesis, si se comparan las figuras de género en el tango tradicional con las del tango prostibulario es indudable que existen diferencias. La "taquera" sobrevive en ciertos rasgos de la mujer que dio "el mal paso", en esa voluntad afirmativa de un sujeto que deja el hogar y toma las riendas de su destino. Pero el tono moralizante que aparece en los tangos tradicionales y el final trágico que siempre espera a estas mujeres, torna oscura y espesa una vida que en las letrillas de los primeros tangos se presentaba con una tonalidad irreverente. La milonguita, cuando "cayó" por amor o por ambición es motivo de compasión por el final desdichado que inexorablemente la encontrará en la vejez; cuando abandona y hace sufrir, es ocasión de recelo y venganza. En este marco, la figura de la madre opera como una contracara que define lo que una mujer debe ser, representa un amor sin parangón ni fisuras, abnegado, sincero, puro, eterno, sacrificado. Madre/buena, mujer/ amante/mala son figuras solidarias entre sí pero por la negativa. Acaso la violencia sea el hilo conductor que las conecta, más allá, claro está, de la figura del hijo/amante, una violencia que se trasluce en el sufrimiento de una madre cuyo único destino es la casa y el sacrificio del trabajo, la espera y el hogar; una violencia que se hace física en la que padecen las otras mujeres cuando son "escarmentadas" por la traición que llevaron a cabo.

\section{Figuras de lo femenino en el tango "verde"}

Las letras del tango no son "reflejo" de la realidad. Configuran una expresión artística que tanto construye como se nutre de aquello que la circunda. A veces esas letras son extemporáneas. Iluminan el presente hablando, como señalábamos antes, de un tiempo que ya pasó, de compadritos que ya no existen, de esquinas que han cambiado. Otras veces reflexionan sobre tópicos existenciales, como el paso del tiempo, la muerte. Analizamos en el apartado anterior las figuras de género ligadas con lo femenino que se articulan 
en las letras de tango tradicional, señalando la transformación que atraviesa desde la protagonista prostibularia hasta la milonguita del cabaret y la madre abandonada. Estas figuras, entonces, tanto se nutrieron de la realidad circundante como ofrecieron un territorio donde configurar el sentido sobre lo que es o debe ser "una mujer", un espejo en el que mirarse, reflejarse, identificarse, o por el contrario, diferenciarse y deconstruirse. Señalamos cómo hasta hace no muchos años los letristas de tango eran principalmente varones y cuando en sus historias aparecían figuras femeninas, lo hacían casi siempre atravesadas por una posición de sujeto de la que sus letristas no se desembarazaban. Así, como señala Dos Santos (2001), las "minas literarias" fueron personajes inventados por los hombres de tango, pero que, agregamos, respondían a una representación sobre lo femenino que circulaba más allá de esa literatura.

Si las mujeres siempre escribieron letras de tango, en el presente asistimos a una novedad que tiene que ver con la extensión del fenómeno y su repercusión, incluso en los medios de circulación masiva. ${ }^{9}$ No se trata sólo de "mujeres" escribiendo tango, sino de un movimiento mucho más amplio que se enlaza, en algunos casos, con las mareas que desde hace unos años colmaron las calles y alcanzaron visibilidad pública. En las últimas décadas se han creado diversas propuestas culturales orientadas a las diversidades sexuales, como el tango gay y queer (Cecconi, 2009 y 2015; Liska, 2009), ligadas fundamentalmente con la danza, que amplían los límites del tango y del género, al abrirse a exploraciones en las que la heteronormatividad es puesta en suspenso. También se han organizado festivales, como el Festival de Tango Queer, o el más reciente Festival Internacional Feminista de Tango, impulsado por Tango Hembra, un colectivo que reúne a músicas, intérpretes, comunicadoras, bailarinas, poetas, escritoras, investigadoras y gestoras de la escena actual tanguera. Este festival y el nombre del colectivo juega con una herencia que busca dar vuelta, invertir el sentido de un tango que siempre se pensó "macho".

Quizás uno de los exponentes más evidentes de la convergencia entre el tango y las corrientes feministas sea la creación del Movimiento Feminista de Tango, una organización que procura llevar adelante diversas acciones para alcanzar la igualdad de género al interior de la comunidad "milonguera", produciendo protocolos de actuación ante casos de violencia de género, entre otras medidas. De alguna manera, el territorio de la danza ha sido pionero en esta cuestión, al menos si consideramos la visibilidad que han alcanzado sus acciones y propuestas. Pero no es el único terreno en donde pueden observarse avances en este sentido. La marea verde avanza y lentamente alcanza otras dimensiones del tango. No es de extrañar, entonces, que las nuevas composiciones se vean también atravesadas por estas cuestiones.

Nos interesa en este apartado realizar el análisis de un corpus de nuevas letras de tango, escritas por mujeres. Estas composiciones abordan numerosos tópicos que retoman los tradicionales. Así, no faltan las referencias a la ciudad y el barrio, tan característicos del tango, aunque la clave en la que se declina en las nuevas letras está decididamente atravesada por la actualidad. Aparecen también referencias a cuestiones sociales, con una presencia mayor que el que el tango tradicional les había otorgado. Y se articulan en ellas figuras de género ancladas en el presente: es en este punto en el que haremos foco, analizando cómo se retoman, tuercen o abandonan aquellos arquetipos de género tradicionales para deconstruirlos y rearmarlos en función de las nuevas claves epocales y 
generacionales, así como indagar en las características, los elementos y las figuras novedosas que se articulan en esas letras.

La primera cuestión sobre la que debemos insistir es que todas las letras que analizaremos han sido escritas por mujeres. Pero no sólo eso, en todas ellas el yo lírico es femenino. De este modo, el escenario que estas letras ofrecen abre una posibilidad de exploración de la subjetividad femenina como representación, presentación y expresión: mujeres hablando de mujeres en las letras del tango contemporáneo. Estas letras tanto se están haciendo eco de la realidad de la que emergen como sirven de canal de articulación y visibilización de esas realidades. $Y$ al hacerlo contribuyen a construir simbólicamente un mundo en el que esa realidad se reafirma como válida. En la lucha por los significantes, qué es "ser mujer" adquiere nuevos ribetes cuando quienes lo definen son... las propias mujeres. Porque de eso se trata: de indagar en las figuras femeninas que se articulan en las letras de tango contemporáneo sin perder de vista quién enuncia. Las mujeres han tomado la voz. Ya no son habladas: hablan. Y al hacerlo definen nuevos contornos para las figuras de género y para el mismo tango.

Si el arquetipo femenino del tango tradicional era una mujer que no tenía voz propia, en este nuevo tango lo que aparece es una que enuncia, grita y proclama su visión y posición y al hacerlo se reafirma como tal. El "yo" lírico, femenino, manifiesta de este modo su distancia respecto de una tradición que no la contiene, que nunca la contuvo:

Cientos, miles de canciones

que me quieren sujetada

al verso de un dolor callado.

A quién se lo decís, gritando voy

ese amor que yo no busco.

A mí no me han escrito un tango,

a mis resueltas soledades,

yo me voy haciendo paria.

Sin letra ni partitura,

deconstruyéndolo al Che,

voy naciendo mujer nueva.

Mujer nueva (Letra Patricia Malanca; Música Mariano Heler)

Y quizás por eso, porque a estas mujeres no les han escrito tangos, ni tienen letras ni partituras, porque no se quieren sujetadas, deciden tomar la palabra y gritar. Y entonces esa nueva mujer contará quién es reafirmándose desde su propia voz, será insolente, se rebelará ante los mandatos que la sociedad patriarcal le ha impuesto en el pasado, será activa, luchará por sus derechos:

Yo soy la que zafó de los mandatos, se rebeló de pie y plantó bandera.

Y se quedó mancándola buen rato A proclamar la lucha de quien era. Yo soy (Letra: Marisa Vázquez; Música: Marisa Vázquez y Anibal Corniglio) 
Una mujer cuyo destino no se avizora en el horizonte del matrimonio, una mujer que navegará independiente hacia su futuro, que si necesita tomar un brazo para andar no será el de un varón que la lleve por un camino que no ha elegido, sino el que la conduzca por los caminos que sus sueños prometieron a sus ansias:

me cuelgo del brazo de mis sueños

a cruzar nuevos mares y caminos.

Del brazo de mis sueños (Letra: María José Demare; Música: Daniel García)

Así, lo femenino en este tango verde se reafirma lejos de los mandatos tradicionales, de la obediencia, la sumisión, la abnegación y la rutina, delineando una mujer que trabaja fuera del hogar y lo hace en posiciones de poder antes exclusivamente ocupadas por varones, una mujer cuyo territorio se distancia del doméstico, tradicionalmente pensado como el ámbito femenino por antonomasia. Esta mujer, además, se subleva ante los mandatos estéticos que procuran definirla como puro objeto o como mera figura decorativa de varones que afirman su virilidad al mostrarlas como trofeo. Tampoco se piensan "suaves", dóciles ni tranquilas como un "campo de hierbas". Esta mujer, en definitiva, se rebela ante esa metáfora constitutiva de la tradición que la piensa como mero desprendimiento, secuela, derivación secundaria, "costilla" del varón, una mujer que ha debidodebido, en ocasiones, masculinarzarse, "ponerse los largos", para enfrentar ese mundo donde el poder es masculino, una mujer que quiere ser amada tal como es, con todas las diferencias que la distancian de aquella noviecita ideal del modelo tradicional. Y esa mujer, aun afirmándose en esa diferencia, puede pensarse y reconocerse en una función primordial que la tradición imponía como su destino y esencia: la maternidad. Pero ese "vientre que da vida" es eso: solo una parte, una posibilidad que puede darse o no, pero que definitivamente no define, ni delimita ni constriñe lo que una mujer es:

La mina que te manda en el trabajo, porque se retobó de ser costilla, y tuvo que ponerse bien los largos. Y soy el vientre que te dio la vida. (...) La loca que no plancha tus camisas, la hembra que no cose tus miserias y soy tu amiga inclaudicable, tu yunta pa' tirar, yo soy tu compañera.

Yo soy (Letra: Marisa Vázquez; Música: Marisa Vázquez y Anibal Corniglio)

No busques que sea un alivio continuo ni fiel a rutinas, ni buena presencia, ni nena obediente ni tonta muñeca ni campo de hierbas.

No sueñes ni pienses o te hagas ideas de eterna caricia o de ave en tu nido, 
no voy a ser foto en tu archivo de muestras,

ni tu pertenencia.

O quereme así o nunca me quieras.

O quereme así o nunca me quieras (Letra: Leda Amorío; Música: Beatriz Palumbo)

Volvamos sobre la cuestión del "vientre" y el modo en que aparece la función maternal en esta nueva letrística. Si en el tango tradicional, como señalamos en el apartado anterior, la madre es un ser idealizado por el hijo, que se opone imaginariamente a la "mala mujer" que abandona al varón, en las letras contemporáneas analizadas en este trabajo la madre adquiere características completamente diferentes.

En primer lugar, la imagen del vientre puede ser leída como una sinécdoque deconstruida: el vientre y la función a la que alude, la maternidad, es solo un aspecto (o puede ser no serlo) de lo que una la mujer es, que se enhebra con muchas otras dimensiones. La parte de un todo que excede, con claridad, esa fracción que lo compone. Para decirlo de otro modo: que todo ser humano posea una madre que es mujer no significa que toda mujer deba convertirse en madre. La ecuación no es reversible. Pero cuando la mujer es madre, en estos tiempos, en estas letras, en el modo en que las mujeres nos pensamos, es una mujer real, no idealizada. Así presentada, la función maternal desde una perspectiva femenina introduce elementos enteramente novedosos para esta figura. La maternidad comienza con el acto de parir. Parir como abrirse, partirse, romperse, imágenes que iluminan ese acto tan visceral que es el de dar a luz. Pero parir también significa todo lo que sobreviene a dar vida, interrogarse, nutrir y criar:

Verdor de futuro que en mí germinó

y fue barrilete de un amor en celo.

Estallé en preguntas, desperté mamá.

Fui raíz gozosa nutriéndote el vuelo.

(...)

Yo anduve de parto partiéndome en dos

y parí el asombro de la primavera.

Tu mano en la mía se animó a tejer

su cielo de alondras camino a la escuela.

Parto (Letra: Patricia Barone; Música: Javier González)

yo anduve amamantando vida nueva.

Palomas (Letra: Patricia Barone; Música: Javier González)

Yo, mujer, plenitud de dar vida y de vivir, abriendo el corazón de par en par,

Yo mujer (Letra y música: Beatriz Villar)

Vamos naciendo, pariendo, inaugurando

la nueva década que nos encuentra unidas

Bisagra (Letra y música: Marcela Bublik) 
En algunas letras, como puede observarse, aparece la mujer en singular, narrando su propia experiencia de convertirse en mamá como hecho personal, con todos los interrogantes que eso supone. No es el hijo sino la mujer la que cuenta cómo es ser madre, sin idealizaciones, con dudas, con preguntas, con temores. En otras ocasiones, la mujer aparece en plural: se trata de "nosotras", de las mujeres que "vamos pariendo". Y cuando esto emerge, lo hace el conjunto de mujeres que inauguran un tiempo nuevo, compañeras, unidas, sororas. Las mujeres van pariendo vida, pero también se van pariendo a sí mismas como un colectivo que busca transformar la realidad:

¿Cómo sonreír si lloras?, ¿cómo ser feliz si sufres?

Caminemos juntas, te regalo una sonrisa,

Comencemos hoy.

Yo mujer (Letra y música: Beatriz Villar)

Ahora estamos juntas ninguna está sola, lastimando a una, nos herís a todas.

Porque ya no existen dolores ajenos

hoy nos duele a todas, no habrá ni una menos.

Gritaremos fuerte por las murieron, por las que callaron, las que no pudieron

escapar a tiempo, juntar el valor

ver que era posible una vida mejor.

Ni una menos (Letra y música: Verónica Bellini)

Lejos de esas imágenes donde las mujeres se enfrentaban y competían, aquí aparecen juntas, empáticas, colectivas. Reverberan en estas letras las luchas de las mujeres que ganaron la calle, el grito que denuncia el dolor y la muerte. Y también las historias que cuentan la violencia de género, los femicidios, las violaciones y los abusos:

La cara golpeada de mi pasado

Llanto con sangre

Porro de Sal

Morder las toallas, las almohadas

Esa cara en el espejo ya no mira para atrás

El secreto oculto bajo la almohada

La mujer golpeada (Letra: María José Demare; música Enrique Nicolas)

Puños fuertes como el hierro

que acarician suavemente,

son tus manos que conmueven

y describen crudamente

el horror de nuestras noches,

el espanto del oyente, 
esa mueca inalcanzable

de un amor que no florece.

Tristes manos de poeta (Letra y música: Eva Fiori)

No te hagás el pobre tipo porque todos ya sabemos

que a vos no te importa un bledo si hacés mal o si hacés bien,

que a la mina que llorabas, arrastrado por las calles,

la fajaste siete veces y la maltrataste cien.

Me dijeron (Letra y música: Claudia Levy)

Vuelve a la mente un flash,

La noche en complicidad.

jadeos y manos

Destruyen su cuerpo y paz.

El asco,

silencio

y el vientre encuentra su verdad.

Pendeja (Letra: Cintia Trigo; Música: Pacha González)

Una noche vi encendida

la luz de la pieza de aquella,

y el instinto -que es de hembra-

me llevó hasta nuestra hija.

Ahí, entre tanta ternura,

destilabas tus terrores.

$\mathrm{Y}$ sin medir los errores,

como leona con su cría,

vacié tu reglamentaria

gritando ¡que ni la toques!

El zarpazo (Letra: Marisa Vázquez; Música: Verónica Bellini)

Estas letras manifiestan entonces el horror del abuso sexual, más todavía el ejercido contra niñas, del cuerpo violentado por golpes, palizas, puños y sangre, y el llanto, el secreto, el silencio y la vergüenza que se transforman en canción, para abrir las puertas de lo oculto y dejar salir hacia el exterior ese espanto que es el de muchas que ahora dicen, salen y luchan y gritan Ni una menos.

De este modo, tanto la mujer empoderada e independiente, como aquella sometida a la violencia machista encuentran lugar en las letras de este tango verde. La mujer empoderada es también aquella que logró romper el círculo de la violencia, que encontró en el apoyo de otras mujeres la fuerza para hablar y salir de las relaciones signadas por golpes y el terror. Así, cuando las letras traslucen los rasgos de una mujer sojuzgada, las letras son expresión de la reciente visibilidad que asumió el movimiento de mujeres con el "Ni una menos". Hay varias letras que asumen esta temática como eje compositivo. Aparece 
en ellas la mujer que ha sido víctima de la violencia de género y que logra abandonar al golpeador, apoyada por una marea de mujeres que la sostienen y la acompañan. No estás sola, dicen unas a las otras. Ni una menos gritan todas, la marea verde del tango se hace canción y la canción, sororidad.

Por la inversa, esta temática también aparece en las letras donde el retratado es el golpeador, ese que pasa de ser "macho" fuerte, seguro, brutal, a pobre infeliz abandonado, que va suspirando su desgracia por la vida. Este varón, lejos de la simpatía que despertaba en los tangos tradicionales, aparece en toda su crudeza: ser ambiguo, que oculta tras la fachada del abandono una violencia que ya dejó de estar invisibilizada para la sociedad. El significado con el que cargan estas figuras masculinas está completamente invertido respecto al que se le atribuía en el tango tradicional. Este varón al que el yo lírico femenino le habla se revela en su pobreza de espíritu, perdido en su soledad violenta, sin vuelo, cobarde, chamuyero, arrogante y vago. Las mujeres ya no se engañan como la "milonguita" que dio el mal paso: seguras de sí, increpan a ese varón que no es lo que aparentaba y lo abandonan para continuar con su vida:

Y comprendí su soledad

al ver su oscuro fondo blanco.

No fue el amor ni fue el espanto

ni sirvo yo para engañar.

Burro taxi, nunca más

pago por un trago tan caro.

Me arrepentí de haber buscado

su ilusa y falsa libertad.

Burro Taxi (Letra: Cintia Barrionuevo; Música: Cintia Barrionuevo y Andrés Drimer)

Qué pasa con vos? Te veo perdido

y, quién lo diría, casi arrepentido.

Te quedaste solo, quién lo iba a pensar,

por fin te ganaron el último round.

Ni una menos (Letra y música: Verónica Bellini)

Llorá, que no hay Cristo que te salve.

Llorá, que llorar te hace tan bien.

Y bajate del caballo y andá poniéndote al día

Y dejá la cobardía de pegarle a una mujer.

Me dijeron (Letra y música: Claudia Levy)

Sos un tipo rebuscado

y no me vengas con el cuento

que las minas exageramos. 


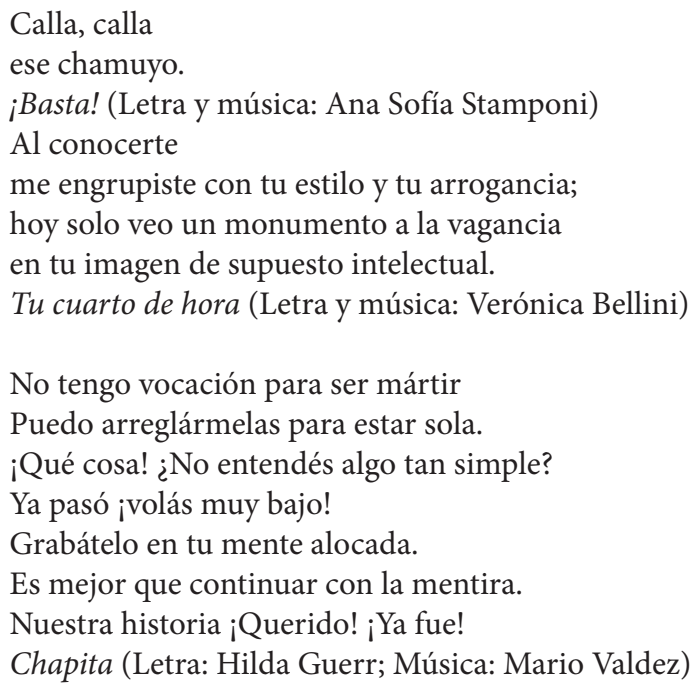

Pero en estas nuevas letras se reconoce también que no esa la única relación afectiva posible con un varón. El amor, el desamor sin violencia, también figuran en ellas. En estos composiciones es una mujer la que relata una pena de amor, toma la palabra para expresar su dolor y su desesperación, o el modo en que siente ante un amor que crece. En todos los casos, más allá del desenlace de la historia, lo que estas letras ponen de manifiesto son relaciones donde la violencia no se asoma, relaciones que son parejas, donde dos adultos se encuentran o desencuentran, gozan o se lamentan del amor que ya no sienten, en un terreno de paridad:

Dame un poco de mí

de todo lo que dí

hasta quedar sin alma.

Devolveme el calor

las ganas de reir

devolveme la calma.

Si yo te dí mi amor y mi verdad,

y a cambio me quedó esta soledad,

Prefiero imaginar que no es que me abandones,

te vas para volver como las estaciones...

Como las estaciones (Letra y música: Verónica Bellini)

El amor se acaba, el dolor se aleja

y queda esta espera que nunca me deja.

Yo te esperé siempre sin esperar nada

y te sigo esperando cada madrugada. 
Cuando nada queda... siquiera tu ausencia, ya sin esperanza, ya sin impaciencia.

En este silencio, mirar sin buscarte... esta espera es todo lo que me dejaste. La espera (Letra y música: Verónica Bellini)

Violenta primavera lo hiciste a tu manera limpié tu corazón de soledad y te perdí y que yo más quisiera que se alivie este dolor borrando las quimeras de tu amor Tango violento (Letra y música: Natalia Lagos)

Aunque tus huestes olvidaron la destreza, aunque tus huesos ya no sean como el gres, cuando hasta el blanco fuga ya de tu cabeza mientras la panza no te deja ver los pies; sigo admirando el resplandor de tus hazañas, sigo buscando algún destello en tu apagón, hallo tesoros en tus quiebres y en tu calma. Soy compañera de tu abismo y de tu sol. A pesar de... (Letra: Mónica Fazzini; Música: Beatriz Palumbo)

Pero estas letras no sólo hablan de amor/desamor sino también de la cuestión del deseo, donde se avizora otro aspecto de las figuras femeninas que da cuenta de la posición activa de sujeto. En el tango tradicional, las mujeres aparecían fundamentalmente como objeto de deseo de los varones. Si la mujer fue representada como "ardiente" -es decir, deseanteen esos tangos, como en el tango inaugural La Morocha (de Villoldo y Saborido, de 1905), lo fue antes del proceso de adecentamiento que el tango atravesó y que erigió las figuras de la madre, de la noviecita fiel y de su opuesto, la mala mujer, como arquetípicas: en el tango tradicional, si la mujer deseaba, entonces era asociada a esta última figura, nunca con la mujer "decente". Es cierto que existen algunos tangos disidentes en este sentido, sobre los que nos ocuparemos enseguida, pero también lo es que ellos conforman una parte ínfima de un universo dominado por la figura de la mujer concebida como objeto de deseo.

Pues bien, en este terreno los tangos contemporáneos escritos por mujeres también inauguran una ruptura, al presentar figuras femeninas que no sólo desean, sino que lo expresan con claridad y desparpajo. Las mujeres deseantes del tango verde se afirman como sujetos activos también en el terreno de la sexualidad. Son apasionadas y, lejos de ese modelo que pensaba en doblegar el deseo femenino y reducir su espacio de expresión al matrimonio, estas mujeres dicen vivir muchos amoríos, se enredan en noches de seducción y se arrojan extasiadas al disfrute de su sexualidad. 
Yo tuve las pasiones florecidas en todos los oasis del planeta.

Palomas (Letra: Patricia Barone; Música: Javier González)

Y soy la que de noche en silencio enreda un desamor en sus caderas, renace cuando llega la mañana y vuelve con su afán para emprenderla. Yo soy (Letra Marisa Vázquez; Música: Marisa Vázquez y Aníbal Corniglio)

Seducidos, arrojados sin remedio y sin miedo en una nube de secretos, de lisérgicos cuerpos que se enredan y se inmolan en un cáliz de deseo.

Embriagados (Letra: Leda Amorín; Música: Beatriz Palumbo)

Cuando dejo de extrañarte de pronto llueve un poquito y es que yo con la llovizna tengo el sí flojito tengo el sí flojito y es que yo con la llovizna tengo el sí flojito, qué le voy a hacer Ranchera en Si flojito (Letra y música: Verónica Bellini)

Como se observa en esta última letra, se trata de mujeres que irónicamente plantean que tienen el "sí flojo", es decir que no andan reprimiendo su deseo y que encuentran en cualquier excusa el motivo para dejarlo fluir. Con este sí "flojo" otrora el tango hubiera construido la figura de una mujer "indecente", quizás deseada por los hombres pero poco "apta para el matrimonio" por su evidente falta de apego a los mandatos de la castidad. En cambio, en estas letras es vehículo para la definición de una mujer que se declara a viva voz apasionada, y es un medio también para expresar a través de un tono a la vez pícaro y sutil, que ese deseo ya no se oculta ni se reprime ni se encorseta en los mandatos de una sexualidad reprimida.

La autora de ese tango encontró una veta expresiva muy interesante para articular la voz de esas figuras femeninas que emergen en estos nuevos tangos. Su apuesta es presentarla con un tono entre travieso e inocente que tanto recupera, en cierto sentido, la visión tradicional de la mujer como rompe con él. En efecto, en esta versión la mujer no aparece moldeada en una figura fuerte, contundente y abiertamente desafiante que otras letras le otorgan. Por el contrario, la estrategia es la de una mujer que en apariencia guarda las formas de la dulzura, la delicadeza y la gracia aniñada que podrían asociarse a la noviecita fiel del tango tradicional. Sin embargo, detrás de esa forma se aviene un discurso que es disruptivo respecto de ella, al trastocar todas esas cualidades en la figura de una mujer que no duda en hacer lo que quiere. 
Así vemos que el humor tampoco está ausente en las nuevas letras de tango escritas por y sobre mujeres. Verónica Bellini y su grupo China Cruel merecen una mención especial en este terreno. Ya el nombre del grupo es alusivo a una intención de jugar con la herencia recibida, de torcer la mirada sobre las figuras tradicionales de género. La "china" no es la "chinita" encantadora, sensible, dócil y sumisa de la tradición, sino una china "cruel", es decir, capaz de hacer sufrir sin sentir remordimiento, lejana de esa mujer sensible, acogedora, maternal. La crueldad es la antítesis de la imagen tanguera de la "madre" y de la "novia", infinitas en su paciencia, en su capacidad de dar amor, de sufrir por el otro, de entender traiciones y abandonos. En cambio la china, cuando es cruel, no es maternal, y si de traiciones y abandonos se trata, es ella la que asume la posición activa en este terreno, traiciona, abandona, deja, huye y vive una vida independiente. Y cuando se sabe abandonada o traicionada, su actitud es decididamente desafiante:

Dice la ley de mi barrio que el que las hace las paga, como vos me hiciste daño seré tu dedo en la llaga. Nací para molestarte (Letra y música: Verónica Bellini)

Así, siguiendo la estela de la picaresca tan rica de Tita Merello, en las letras compuestas por esta generación de autoras, todas las figuras tradicionales de género se hacen presentes pero a la vez se tuercen. En este caso, se citan para ser parodiadas, desafiadas, cuestionadas, con una cuota de ironía que pone en entredicho todo lo que la tradición tenía para afirmar de estas figuras. Pero también se introducen otras figuras que no aparecían tanto en las letras de tango como en la discursividad social, que eran evidentemente solidarias de las figuras tradicionales. Entre ellas podemos mencionar a la "solterona", aquella tía que toda familia supo conocer que no pudo "encontrar marido" y quedó sola para "vestir santos". En estas letras, la solterona abandona la posición pasiva de mujer indeseada y solitaria para transformarse en una milonguera que activamente aprovecha cada ocasión para el disfrute, el baile y la diversión:

En el barrio ya me han dado el carnet de solterona mis amigas de la infancia ya se han vuelto unas matronas y yo sigo en la carrera quiero tiempo pa elegir no es cuestión de agarrar viaje cuando llega el primer gil Sin apuro pa'l casorio, para qué apurar al tiempo total nunca me ha faltado con quien pasar el invierno y mientras el cuerpo aguante quiero ir a milonguear hasta estar bien achacada ni me arrimo pa' un altar Solterona (Letra y música: Verónica Bellini)

Más liviana y sin mandatos que el que dictan las entrañas. la pobre solterona es cuento, 
le temen a lo suelto y a lo impar.

No me quiero arrepentida,

a mí me deseo errante,

arcilla sin rubor.

Sobrándole a la piel

lo que no se puede domar.

Mujer nueva (Letra: Patricia Malanca; Música Mariano Heler)

Como vemos, las mujeres que estos tangos muestran se alejan de las figuras de lo femenino que el tango tradicional les otorgó. Esta nueva mujer, que no se arrepiente, que no se deja dominar, ha tomado la palabra también en el tango.

\section{Palabras finales}

El recorrido que hicimos en este trabajo pone en evidencia una clara transformación. En las letras actuales de tango escritas por mujeres, los arquetipos y figuras tradicionales de género se han visto desarticulados por completo.

Aparece en ellas una mujer empoderada, dueña de su destino, segura de sí, independiente. Una mujer que resuelve qué hacer, con quién, cómo. Que decide, que va y que viene. Que desafía los mandatos tradicionales, que sueña, que lucha por sus derechos. Que puede permanecer soltera, o apostar por una pareja. Que toma la palabra.

$\mathrm{Y}$ al hacerlo puede hablar y expresarse con voz propia, contando amores y desamores, alegrías y tristezas, pesares y sueños, a diferencia de lo que ocurría en el tango tradicional donde, si esa voz existía, era apenas un susurro.

Estas mujeres no susurran. Gritan. Gritan ;Basta!, Ni una menos, Yo soy, Mujer nueva. Se solidarizan entre sí, construyen unidas una red que las contiene, se acompañan en la denuncia de la violencia, increpan al golpeador, al violador, al machirulo. Mujeres que paren y se parten en una maternidad elegida, que se representa con amorosidad pero sin idealizaciones. Mujeres activas, que son sujetos deseantes, de una sexualidad que exploran y gozan sin culpa.

Qué queda de aquellas figuras femeninas del tango tradicional, de la madre abnegada, de la novia sumisa, de la "osada" que se atrevió a dar "el mal paso"... no mucho, por no decir nada. En la pluma de las nuevas letristas de tango, las figuras de género se han trastocado. Cuando las mujeres toman la palabra, el tango cambia de tono, pero también de color. Estamos ante un tango verde. Un tango escrito por mujeres que visibilizan una mirada propia con registros que van desde voces prácticamente testimoniales hasta las apuestas por la ironía y la parodia, desde la picaresca hasta la sobriedad, desde la búsqueda de la rima perfecta hasta el verso descarnado.

El arco expresivo de estas letras es enorme, múltiple, diverso. Pero se asoma en esa pluralidad una experiencia común que es la experiencia de muchas mujeres, cuya mirada recoge, versifica y visibiliza. En el conjunto de las composiciones de tango, las nuevas son apenas una gota en un océano con más de un siglo de historia. Resultan, por el momento, 
escasas, pero aun así extraordinariamente significativas. Pues contribuyen a acrecentar un acervo poético que se renueva con figuras que actualizan representaciones. Quizás se encuentre en este tango, capaz de hacer eco en sus versos de las experiencias del presente, la clave para potenciar su capacidad para interpelar a las nuevas generaciones.

Es curiosa la sincronicidad que el mundo a veces nos regala. Estoy terminando este escrito el 9 de marzo de 2020. Ayer fue el Día de la Mujer. Hoy marchamos para seguir gritando \#Ni una menos, \#Viva nos queremos. Queda mucha marcha por delante, pero sin lugar a dudas algo ya ha cambiado. Lo vemos en la calle, en las chicas y los chicos más jóvenes para quienes la paridad de género se percibe cada vez más como algo propio del sentido común. Las mujeres nos estamos transformando. Las relaciones de género se están transformando. Y esta realidad ha llegado al tango.

El tango verde avanza lentamente, pero sin detenerse. Se nutre de la fuerza hembra que ha tomado las calles, de la seguridad que otorga la sororidad que las recorre, de la decisión firme de que sea una voz propia la que se exprese en sus letras para delinear figuras que representen lo que las mujeres sienten, dicen y piensan que son, desnaturalizando el lugar de sumisión, sanción o tragedia que tradicionalmente se les otorgaba cuando desafiaban las normas de la sociedad patriarcal.

El tango en la marea verde se renueva. Y aunque una transformación de estas características puede, sin dudas, disgustar a los guardianes de la tradición, no parece que pueda ser detenida. Su caudal se acrecienta, su marcha no se detiene. Y el tiempo y la renovación generacional harán lo suyo.

\section{Notas}

1. Sin dejar de tomar en cuenta, desde ya, a todos los matices y diversidades existentes. Algunas feministas plantean que, en cierto sentido, todos los feminismos son posgénero, en tanto pretenden desembarazarse de los efectos normativos que efectúa sobre los sujetos. Cfr. Rodríguez Magda $(2019,53)$.

2. Entre otras pueden mencionarse a Rosita Quiroga, Azucena Maizani y María Luisa Carnelli, quien firmaba como Mario Castro o Luis Mario. Para un interesante análisis de la producción de Carnelli puede consultarse Abbate (2019).

3. Dos clásicos interpretados por Tita Merllo, por citar algunos, son Los amores con la crisis (de Francisco Canaro e Ivo Pelay, 1934), Se dice de mí (de Francisco Canaro eIvo Pelay, 1943)

4. Anticipamos al lector que en este apartado no citaremos tangos que ilustren las figuras de género en el tango tradicional. Para ello, remitimos a la bibliografía que citamos en los que encontrarán abundantes ejemplos.

5. Son numerosas las investigaciones que se han detenido en el análisis de estas figuras. Entre las más recientes puede mencionarse a Dos Santos (2001) o Saikín (2004), quien menciona la dicotomía madre-buena/mujer-mala como eje estructurante de las figuras de género femenino en el tango tradicional. Por otra parte, la estructura familiar del tango está lejos de ser la tradicional. Con acierto Saikín habla de una estructura "desvastada”: no 
hay padre en estas historias, las madres siempre están solas, algo que la autora interpreta atribuyendo a esas madreas un pasado non-sancto de prostitución y abandono.

6. Si bien es indudable la dificultad de analizar este período, existen algunas fuentes que brindan un panorama claro, como así también textos y análisis literarios, y documentos periodísticos y judiciales donde indagar cuestiones vinculadas con el tango. En un texto aun no publicado, trabajo especialmente este período del tango valiéndome de este tipo de datos (Cecconi, mimeo).

7. Además de Saikin, pueden consultarse Tallon (1964), Matamoro (1969 y 1971), Gobello (1976), Salas (1986), Guy (1994), Savigliano (1995) y Salessi (1997), entre otros.

8. Ver Matamoro (1971) y Tallón (1964) respectivamente

9. El periódico Página/12 publicó una nota sobre esta novedad a comienzos de marzo de 2020. Puede consultarse en https://www.pagina12.com.ar/250637-las-letristas-del-tangohoy-sentimos-la-necesidad-de-decir-o

\section{Bibliografía}

Abbate, Florencia (2019). "María Luisa Carnelli: La primera letrista de tango-canción" en El jardín de los poetas. Revista de teoría y crítica de poesía latinoamericana. Año V, n ${ }^{\circ} 8$, primer semestre de 2019. pp19-43. Disponible en https://fh.mdp.edu.ar/revistas/index. php/eljardindelospoetas/article/viewFile/3679/3656

Archetti, Eduardo (1998). "Masculinidades múltiples. El mundo del tango y del fútbol en Argentina”. En: Balderston, Daniel y Donna Guy (comp). Sexo y sexualidades en América Latina. Buenos Aires, Paidós, pp. 291-312.

(2003). Masculinidades. Fútbol, tango y polo en la Argentina. Buenos Aires, Antropofagia.

Butler, Judith (2001). Géneros en disputa. El feminismo y la subversión de la identidad. Buenos Aires: Paidós

(2005). Cuerpos que importan. Sobre los límites materiales y discursivos del cuerpo. Buenos Aires: Paidós

Cecconi, Sofía (2009). “Tango Queer: territorio y performance de una apropiación divergente", artículo en Revista Transcultural de música/Transcultural Music Review con referato internacional. (ISSN 1697-0101), Nro. 13, 2009, publicación electrónica disponible en http://www.sibetrans.com/trans/trans13/art05.htm

(2015). "Performance y performatividad de género en el tango queer" en Szir, Sandra; Dolinko, Silvia; Marchesi, Mariana: Imagen/Deseo. Placer, devoción y consumo en las artes, Centro Argentino de Investigadores en Artes, Buenos Aires, pp. 309-321. prostibulario".

(mimeo). "Corporalidades y sexualidades no normativas en el tango

De Lauretis, Teresa (1987). Technologies of gender. Indiana University Press.

Dos Santos, Estela (2001). Damas y milongueras del tango, El Corregidor, Buenos Aires.

Gobello, José (1976): "Orígenes de la letra de tango". En: AAVV: Historia del Tango. Sus orígenes. Buenos Aires: Ediciones Corregidor. 
Guy, Donna (1994). El sexo peligroso. La prostitución legal en Buenos Aires 1975-1955. Buenos Aires: Sudamericana

Liska, María Mercedes (2009). "El tango como disciplinador de cuerpos ilegítimos-legitimados" en Revista Transcultural de música/Transcultural Music Review Nro. 13, 2009, disponible en http://www.sibetrans.com/trans/a53/el-tango-como-disciplinador-decuerpos-ilegitimos-legitimados

Matamoro, Blas (1969). La ciudad del tango. Buenos Aires, Galerna.

(1971). Historia del Tango. Buenos Aires, Centro Editor de América Latina.

Rodríguez Magda, Rosa María (2019). La mujer molesta. Valladolid, Editorial Ménades.

Rubin, Gayle (1986). "El tráfico de mujeres: para una economía política del sexo", en Revista Nueva Antropología, México DF, UNAM.

Saikín, Magalí (2004). Tango y género: identidades y roles sexuales en el tango argentino. Stuttgart, Abrazos Books.

Salas, Horacio (1986). El tango. Buenos Aires: Planeta

Salessi, Jorge (1997). "Medics, Crooks, and Tango Queens: The National Appopriation of a Gay Tango". En: Fraser Delgado, Celeste y J. Muñoz. Everynight Life. Culture and Dance in Latino/a America. Durham: Duke University Press.

Savigliano, Marta (1995). Tango and the Political Economy of Passion. Colorado: Westview Press

Tallón, José Sebastián (1964 [1959]). El tango en sus etapas de música prohibida. Buenos Aires, Ulla, Noemí (1982 [1967]). Tango, rebelión y nostalgia. Buenos Aires. Centro Editor de América Latina.

Vilariño, Idea (1965). Las letras de tango. La forma, temas y motivos. Buenos Aires, Editorial Schapire SRL.

Tango in the green tide. A gender perspective on the figures of the feminine in today's tango

Abstract: the tango lyrics are a privileged territory for the manifestation of several gender figures. Some of them have become classic: the milonguita, that woman with aspirations of social ascent that leaves the neighborhood in search of a better life; and the mother, selfless woman, perfect in the eyes of the son. Since the consolidation of those figures in the tango lyrics, many years have passed and the traditional conception of gender differences has been transformed. This article analyzes the way in which those traditional female figures are recovered, distorted and been broken in the new tango lyrics written by women, lyrics that introduce new voices and colors into the tango. The "green" tango is a contemporary tango in which the dialogue with feminism is possible.

Keywords: tango - gender - tango lyrics - feminism - woman - mother - milonguita. 


\section{Tango na maré verde. Uma perspectiva de gênero nas figuras do feminino no tango de hoje}

Resumo: a letra do tango tem sido um território privilegiado para a manifestação de várias figuras de gênero. Entre as mulheres, algumas se tornaram clássicas: a milonguita, aquela que aspira a um progresso social que sai do bairro e foge para o centro em busca de uma vida melhor, sempre desaprovada pela moralidade dominante; e a mãe, uma mulher que se sacrifica, boa e perfeita aos olhos do filho, capaz do maior sacrifício pela felicidade dos outros. Ambas as figuras, a heroína materna e a contra-heroína milonguita, foram nutridas e cristalizadas em um imaginário social que concebia as mulheres com base em um esquema binário: a boa mulher era a mulher-mãe, orientada para a vizinha, sempre pronta para se colocar. em segundo plano. E, por outro lado, a mulher má foi quem fugiu não apenas de seu destino de classe, mas também de seu gênero, aquele que deixou sua casa natal sozinha, sempre tentada por homens que lhe prometeram uma vida melhor. Na narrativa clássica do tango, essa mulher alegre, desafiadora das normas morais e dominantes, opõe-se pelo vértice àquele que renuncia a um destino autônomo, dois lados de uma moeda que apresenta mulheres ocupando um lugar claro naquele esquema regulatório.

Desde o surgimento e consolidação das letras de tango dessas figuras, alguns anos se passaram e uma maré de experiências que perturbaram as formas tradicionais de conceber diferenças de gênero. Nas últimas duas décadas, testemunhamos um ressurgimento do tango em suas muitas facetas: o tango dançado proliferou em milongas e espaços de reunião; A produção musical do Tango foi revitalizada com uma multiplicação de registros e propostas que ampliam suas fronteiras; e a música de tango também viu sua herança aumentar graças à contribuição de novas gerações de letristas que incorporam novos olhares e tropos. Uma dessas contribuições vem da produção de mulheres, que escrevem letras de tango adotando esses arquétipos de gênero para desconstruir e rearmá-las de acordo com as novas chaves da época. Neste artigo, analisaremos como essas figuras clássicas do feminino são apresentadas nessas novas produções; o papel atribuído às mulheres; e de maneira mais geral, a maneira pela qual as novas letras de tango se recuperam, distorcem e quebram a tradição apresentando figuras femininas. Faremos isso a partir da análise de um corpus de letras produzidas por mulheres, produções que introduzam novas vozes e imaginários no gênero musical e colorem o tango com novas cores. O tango "verde" é um tango contemporâneo que expressa e ao mesmo tempo constrói um novo imaginário, um tango no qual o diálogo com o feminismo é visto como um caminho possível.

Palavras-chave: tango - gênero - figuras de gênero - letras de tango - feminismo - mulher - mãe - milonguita.

[Las traducciones de los abstracts fueron supervisadas por el autor de cada artículo] 